\title{
Effect of strontium ranelate on pain behavior in an experimental model of osteoarthritis
}

\author{
T.A. Rodrigues, A.J.B. Sampaio Junior, I.D.P. Nunes, M.S.S. Cartágenes and J.B.S. Garcia \\ Centro de Ciências Biológicas e da Saúde, Universidade Federal do Maranhão, São Luís, MA, Brasil
}

\begin{abstract}
Strontium ranelate (SrRan) is a drug usually prescribed to treat osteoporosis, with proven effects of decreasing the risk of fractures and an indication of reducing the progression of osteoarthritis (OA). This study aimed to investigate the effects of SrRan as either a prophylactic or a treatment drug, using an OA rat model to assess pain behavior. A monoiodoacetate (MIA)induced knee joint OA model in Wistar rats was used. Thirty Wistar rats (both sexes, 60 days old) were distributed in five groups of 6 rats each: the control group, that received no intervention; a prophylactic group, that received oral administration of $25 \mathrm{mg} \cdot \mathrm{kg}^{-1} \cdot$ day $^{-1}$ of SrRan for 28 days before induction of OA; a group treated with $25 \mathrm{mg} \cdot \mathrm{kg}^{-1} \cdot$ day $^{-1}$ of SrRan for 28 days after OA induction; a group treated with $50 \mathrm{mg} \cdot \mathrm{kg}^{-1}$. day ${ }^{-1}$ during 28 days after OA induction; and a group that received oral saline for 28 days after induction. The assessment of pain behavior was performed considering articular incapacitation (weightbearing test), mechanical hyperalgesia (Randall Selitto test) and motor activity (rotarod test), on days $0,7,14,21$, and 28. This experiment did not yield a significant difference when comparing the group that received SrRan prophylactically with the groups treated with 25 or $50 \mathrm{mg} \cdot \mathrm{kg}^{-1} \cdot \mathrm{day}^{-1}$ and the group that received oral saline. Thus, SrRan did not provide analgesia in either treated rats or as a prophylactic drug with the tested doses. Higher doses should be tested further to achieve possible significant results.
\end{abstract}

Key words: Osteoarthritis; Strontium ranelate; Pain; Treatment; Prophylaxis

\section{Introduction}

Advances in the understanding of the pathophysiology of osteoarthritis (OA), such as the influence of biochemical stress or abnormal intra-articular biomechanics, and the inflammatory pathways involved, have allowed for a considerable increase in therapeutic targets for the disease. Some medications have been associated with reduction of cartilaginous lesions and decreased subchondral bone remodeling, changing the progression of OA (1-5). These drugs, known as disease-modifying osteoarthritis drugs (DMOADs), present the properties of reversing, stabilizing, or at least delaying the course of OA. Oral DMOADs of note include chondroitin (6), diacerein (7), glucosamine (8), glucosamine combined with chondroitin (9), and chloroquine (10). Among the intra-articular treatments, viscosupplementation with hyaluronic acid (11) is also worth highlighting.

Studies have been conducted to increase the number of medications that effectively reduce the progression of $\mathrm{OA}$. The drug strontium ranelate has shown promising results in the prevention of fractures and treatment of osteoporosis in postmenopausal women (12-14), indicating its probable utility in the treatment in OA $(2,15-17)$.
Strontium (Sr, group II of the periodic table with atomic number $=38$ ) is a fundamental element. Its nucleus is similar in size to calcium, making it easily absorbed, carried, and incorporated into bones, as is calcium (15). Its ability to decrease pain and increase bone density was first assessed radiographically in 1959, in a small study including patients with osteoporosis treated with strontium lactate (18). Thus, it has already been used in the treatment of osteoporosis for decades (19).

Currently, strontium ranelate (SrRan $-\mathrm{C}_{12} \mathrm{H}_{6} \mathrm{~N}_{2} \mathrm{O}_{8} \mathrm{SSr}_{2}$ ) is indicated for the treatment of severe $\mathrm{OA}$ and osteoporosis, especially in postmenopausal women with a high risk of fractures $(16,19-21)$. It has also been postulated that SrRan inhibits the resorptive activity of osteoblasts, thus reducing the synthesis of metalloproteinase. In addition, it modulates the osteoprotegerin-RANKL (receptor activator of nuclear factor kappa-B ligand) signaling pathway, and inhibits osteoclastic differentiation (15). SrRan has also been associated with the formation of cartilaginous matrix. Recent data show that it can reduce the progression of radiological findings in spinal OA, along with leading to improvement of lower back pain in women with osteoporosis (15). 
Although SrRan shows the ability to reduce the progression of OA, few relevant studies have been published to date. Therefore, the present study aimed to test the effects of SrRan in an experimental animal model of OA induced by intra-articular injection of sodium monoiodoacetate (MIA). Clinical assessment of motor activity, articular incapacitation, and mechanical hyperalgesia was conducted.

\section{Material and Methods}

This study was conducted in the Experimental Laboratory for Pain Study (LEED) following approval from the Animal Ethics Committee of the Universidade Federal do Maranhão (CEUA-UFMA No. 23115.012456/2016-4).

\section{Animals}

Thirty Wistar rats, Rattus norvegicus species (albino variety), were used in the study. The animals were male and female adults, approximately 60 days old. This study did not aim to evaluate differences between genders. The rats were obtained from the Central Animal Facility of the Universidade Federal do Maranhão. The animals remained in cages and were housed at the LEED lab, where they were fed standard chow and water ad libitum and maintained under controlled conditions of light and temperature.

\section{Experimental design}

The animals were divided into five groups (PROF25, SR25, SR50, SAL, and Control), with 6 rats each. Group PROF25 (prophylactic group) began treatment with SrRan 4 weeks prior to the induction of OA with sodium MIA. SrRan was administered in a dose of $25 \mathrm{mg} / \mathrm{kg}$ by gavage, once daily in the morning, two hours before the subsequent feeding. Groups SR25 and SR50 (treatment groups) received $25 \mathrm{mg} / \mathrm{kg}$ and $50 \mathrm{mg} / \mathrm{kg}$ of SrRan, respectively, starting from day 7 after $\mathrm{OA}$ induction, by gavage, once daily in the morning, $2 \mathrm{~h}$ before subsequent feeding, for a period of 4 weeks. Group SAL received $0.9 \%$ saline solution by gavage after OA induction. The day of OA induction in groups PROF25, SR25, SR50 and SAL was considered day zero (D-0). The Control group did not undergo OA induction nor received intervention. The administered doses in that model were chosen based on previously described animal models using SrRan (15). Throughout the experiment, all groups were periodically evaluated for articular incapacitation, motor activity, and mechanical hyperalgesia on days $0,7,14,21$, and 28 , as described below.

\section{Model of osteoarthritis induced by sodium monoiodoacetate}

To induce $\mathrm{OA}$, the animals were anesthetized using an intraperitoneal injection of $40 \mathrm{mg}$ of sodium thiopental. The joint injury was induced with a single intra-articular injection of $2 \mathrm{mg}$ of sodium MIA into the right knee, diluted in a maximum volume of $25 \mu \mathrm{L}$ solution $(22,23)$.

\section{Evaluation of motor activity - forced ambulation (rotarod test)}

The animals were placed on a rotarod (IITC Life Science, USA) at a speed of $16 \mathrm{rpm}$ for a period of $300 \mathrm{~s}$. The use of the affected limb was evaluated through forced ambulation. The use of the affected paw was graded by a subjective measure, on a numerical scale ranging from 5 to 1 , in which: $5=$ normal use of the paw; $4=$ =mild limping; $3=$ severe limping; 2=intermittent disuse of the affected paw; 1=complete disuse of the affected paw (24).

\section{Incapacitation test - distribution of weight on the hindpaws (weight bearing test)}

The animals were placed in a glass chamber, angled and positioned so that each hindpaw rested on a different platform. The weight exerted on each hindpaw (measured in grams) was evaluated over a period of $5 \mathrm{~s}$. The final weight distribution was calculated using the average of three measurements. The variations in distribution of the weight on the hindpaws were calculated using the following formula:

$$
\text { Weight distribution }(\%)=\frac{A P W}{A P W+C P W} \times 100
$$

where APW was affected paw weight and CPW was contralateral paw weight.

\section{Mechanical hyperalgesia (Randall Selitto test)}

The Randall Selitto test is a useful test to evaluate the hypernociception, based on the induction of hyperalgesia by the increasing paw pressure using a special device. Mechanical hyperalgesia was assessed using the nociceptive paw-withdrawal threshold (NPWT) to mechanical pressure using an analgesy-meter (IITC Life Science) $(25,26)$ in both paws, and then calculating the mean of three measures. The paw withdrawal reflex is considered representative of the hypernociceptive threshold. The NPWT was recorded in grams for both paws, and then the percentage was calculated using the results of affected and contralateral paws, with the following formula:

$$
\text { NPWT }(\%)=\frac{N A P W T}{N A P W T+N C P W T} \times 100
$$

where NAPWT is nociceptive affected paw-withdrawal threshold and NCPWT is nociceptive contralateral pawwithdrawal threshold.

\section{Statistical analysis}

Comparison of the means of different experimental groups was performed using the Student's $t$-test or univariate analysis of variance (one-way ANOVA), followed by the Bonferroni's test. A value of $P<0.05$ was considered indicative of significance and the data obtained were analyzed using the GraphPad Prism ${ }^{\circledR}$ software, version 6.00 for Windows (USA). 


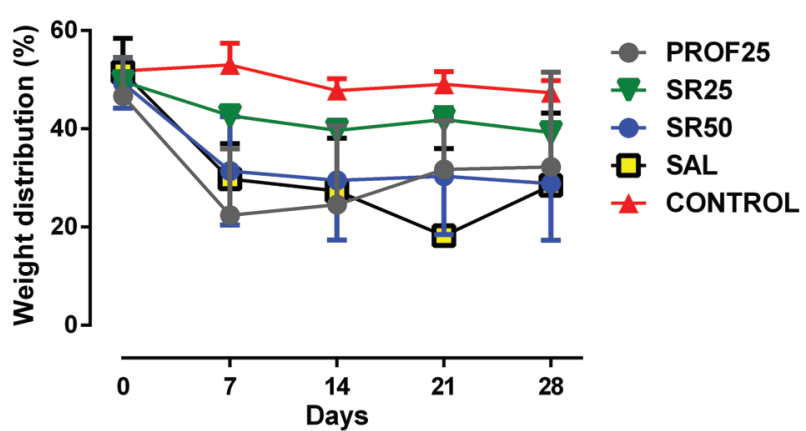

Figure 1. Evaluation of articular incapacitation using the weight bearing test. Group PROF25: administration of prophylactic $25 \mathrm{mg} / \mathrm{kg}$ of strontium ranelate (SrRan) 4 weeks prior to the induction of monoiodoacetate (MIA)-induced osteoarthritis (OA); Groups SR25 and SR50 (treatment groups) received $25 \mathrm{mg} / \mathrm{kg}$ and $50 \mathrm{mg} / \mathrm{kg}$ of SrRan, respectively, after OA induction for a period of 4 weeks; SAL: MIA-induced OA receiving only saline; Control group: no treatment and no OA induction. Results are reported as means $\pm S D$. $P<0.05$ between groups PROF25, SR25 and SR50, and Control; $P>0.05$ between those groups and SAL (one-way ANOVA, followed by the Bonferroni's test)

\section{Results}

\section{Evaluation of articular incapacitation}

The analysis of data regarding articular incapacitation, assessed using the weight bearing test, demonstrated that the OA induction was effective, as we observed a statistically significant difference between the OA group that received saline (group $S A L$ ) and Control group (healthy animals that received saline). A statistically significant difference was observed between the PROF25 (prophylactic) group and the Control group $(P<0.05)$. However, no difference was observed between groups PROF25 and SAL. These results showed that the animals that received SrRan prior to OA induction did not approach the healthy standard of the Control group, nor were they significantly different from those that received saline (Figure 1).

We observed a difference between the groups that received 25 and $50 \mathrm{mg} / \mathrm{kg}$ SrRan (SR25 and SR50), and the group of healthy animals (Control). These groups did not significantly differ from group SAL (Figure 1).

\section{Evaluation of motor activity/forced ambulation}

The rotarod test showed that the OA induction was effective, resulting in a statistically significant difference between groups SAL and Control. We also observed a statistically significant difference between the PROF25 and the Control groups. The same difference was found between the groups that received treatment with SrRan (SR25 and SR50) and the Control group. A difference was not observed between groups PROF25 and SAL, SR25 and SAL, or SR50 and SAL. These findings indicated that there was no change between the animals receiving SrRan and those receiving only saline (Figure 2 ).

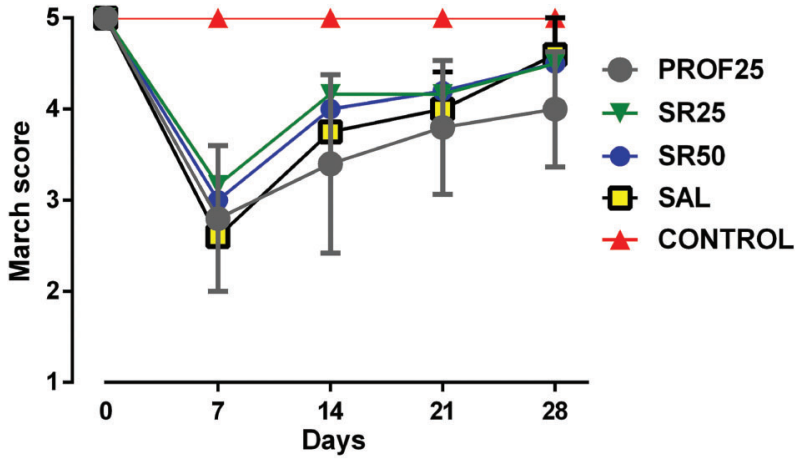

Figure 2. Evaluation of motor activity/forced ambulation using the rotarod test. Group PROF25: administration of prophylactic $25 \mathrm{mg} / \mathrm{kg}$ of strontium ranelate (SrRan) 4 weeks prior to the induction of monoiodoacetate (MIA)-induced osteoarthritis (OA); Groups SR25 and SR50 (treatment groups) received $25 \mathrm{mg} / \mathrm{kg}$ and $50 \mathrm{mg} / \mathrm{kg}$ of SrRan, respectively, after OA induction for a period of 4 weeks; SAL: MIA-induced OA receiving only saline; Control group: no treatment and no OA induction. Results are reported as means $\pm S D$. $P<0.05$ between groups PROF25, SR25 and SR50, and Control; $P>0.05$ between those groups and SAL (one-way ANOVA, followed by the Bonferroni's test).

\section{Evaluation of mechanical hyperalgesia}

Evaluation of hyperalgesia by means of the Randall Selitto test also showed that the OA induction was effective, with a statistically significant difference observed between groups SAL and Control. A statistically significant difference was also found with this test between the prophylactic group and the healthy group. In addition, a difference was observed when comparing the groups treated with SrRan (SR25 and SR50) and the group consisting of healthy animals (Control). We did not observe any difference between the prophylactic group, groups receiving treatment, and group SAL (Figure 3).

\section{Discussion}

The present study assessed pain behavior in an experimental model of OA, using a drug that has been studied as a potential pharmaceutical to be included in the class of DMOADs.

At the administered doses and with the tests employed, there was no observed improvement with the use of SrRan in cases of established OA. This outcome differs from the findings of another study in which $O A$ was induced in rats by zymosan. In that case, the animals were treated with higher doses of SrRan than in our study, ranging from 30 to $300 \mathrm{mg} / \mathrm{kg}^{-1}$. day ${ }^{-1}$ for a shorter period of time (27). The difference could be probably attributed to the different model applied, with higher doses used in that study.

The choice of the SrRan doses administered in our study was based on a study with dogs that underwent $O A$ induced by the section of the anterior cruciate ligament. 


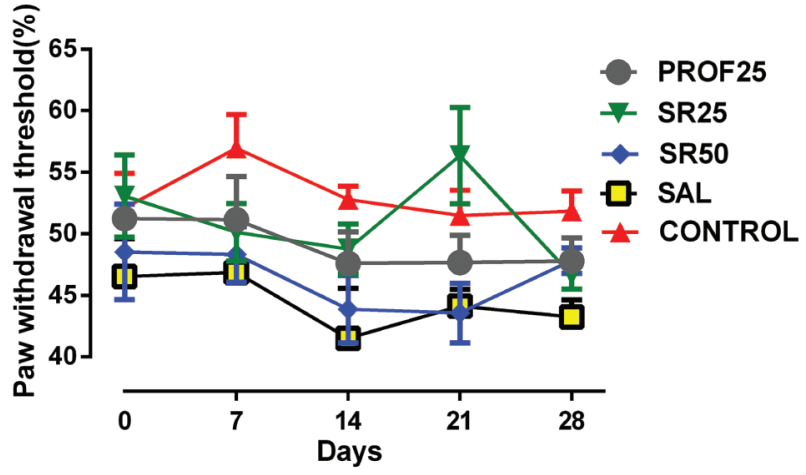

Figure 3. Evaluation of mechanical hyperalgesia using the Randall Selitto test. Group PROF25: administration of prophylactic $25 \mathrm{mg} / \mathrm{kg}$ of strontium ranelate (SrRan) 4 weeks prior to the induction of monoiodoacetate (MIA)-induced osteoarthritis (OA); Groups SR25 and SR50 (treatment groups) received $25 \mathrm{mg} / \mathrm{kg}$ and $50 \mathrm{mg} / \mathrm{kg}$ of SrRan, respectively, after OA induction for a period of 4 weeks; SAL: MIA-induced OA receiving only saline; Control group: no treatment and no OA induction. Results are reported as means $\pm S D$. $P<0.05$ between groups PROF25, SR25 and SR50, and Control; $P>0.05$ between those groups and SAL (one-way ANOVA, followed by the Bonferroni's test).

The doses used were 25,50 , or $75 \mathrm{mg} / \mathrm{kg}$ for a longer period (12 weeks, beginning 4 weeks after the surgery) than in our study (15). That study was the first to demonstrate in vivo the effect of SrRan in reducing the OA progression. The main differences between our study and the above one were the OA induction method and the duration of the treatment. Such differences could have influenced the varying results between the studies.

The prophylactic effect of SrRan was not shown in this experimental study using a model of MIA-induced OA. We did not observe a reduction in articular incapacitation after OA induction, nor was there an improvement in the motor

\section{References}

1. Varady NH, Grodzinsky AJ. Osteoarthritis year in review 2015: mechanics. Osteoarthritis Cartilage 2016; 24: 27-35, doi: 10.1016/j.joca.2015.08.018.

2. Kwan TS, Lajeunesse D, Pelletier J, Martel-Pelletier J. Targeting subchondral bone for treating osteoarthritis: what is the evidence? Best Pract Res Clin Rheumatol 2010; 24: 51-70, doi: 10.1016/j.berh.2009.08.004.

3. Rezende MU, Gobbi RG. Tratamento medicamentoso da osteoartrose do joelho. Rev Bras Ortop 2009; 44: 14-19, doi: 10.1590/S0102-36162009000100002.

4. Lane N, Brandt K, Hawker G, Peeva E, Schreyer E, Tsuji W, et al. OARSI-FDA initiative: defining the disease state of osteoarthritis. Osteoarthritis Cartilage 2011; 19: 478-482, doi: 10.1016/j.joca.2010.09.013.

5. Bijlsma JWJ, Berenbaum F, Lafeber FPJG. Osteoarthritis: an update with relevance for clinical practice. Lancet 2011; 377: 2115-2126, doi: 10.1016/S0140-6736(11) 60243-2. response in the group that received $25 \mathrm{mg} / \mathrm{kg}$ SrRan for 1 month prior to OA induction. Otherwise, the prolonged prophylactic use of SrRan has already been shown to be associated with a reduced fracture risk in some clinical trials, especially in postmenopausal women with osteoporosis $(13,21)$. It has been suggested that this prophylactic effect is due to an anti-resorptive and pro-formation action in bone metabolism processes $(14,21)$.

The exact mechanism of action of the substance is not entirely clear (17). However, the regulation of bone cell differentiation, the stimulation of osteoblast proliferation, and the inhibition of osteoclast formation with probable apoptosis of "mature" cells have been suggested as possible mechanisms, in addition to the activation of receptors sensitive to calcium - the latter being the most probable $(17,19,28-30)$. It has also been shown in vitro that SrRan increases the synthesis of collagen and noncollagenous proteins, improves the proliferation of preosteoblast cells, and that it should, therefore, be classified as a bone-forming agent (20).

At the doses used in the present study, SrRan did not promote analgesia in the treatment and prophylactic groups. There was no improvement in pain behavior in the animals studied, with no impact on articular mobility, motor activity, or mechanical hyperalgesia in comparison to the control group. This finding could be related to the doses used in this experimental model, which were smaller than those used in other studies on this drug, varying from 300 to $625 \mathrm{mg} / \mathrm{kg}(27,31)$. That could probably be a limitation of our study, including the time period of medication usage. Experimental improvements were obtained with higher doses $(27,31)$ and for longer periods $(15,31)$. This experimental model determined that additional studies examining the use of SrRan in the treatment of OA are required, particularly investigations using higher doses of this drug.

6. Hochberg MC, Zhan M, Langenberg P. The rate of decline of joint space width in patients with osteoarthritis of the knee: a systematic review and meta-analysis of randomized placebocontrolled trials of chondroitin sulfate. Curr Med Res Opin 2008; 24: 3029-3035, doi: 10.1185/03007990802434932.

7. Fidelix TS, Soares BG, Trevisani VF. Diacerein for osteoarthritis. Cochrane Database Syst Rev 2006; 25: CD005117, doi: 10.1002/14651858.CD005117.pub2.

8. Towheed TE, Maxwell L, Anastassiades TP, Shea B, Houpt J, Robinson V, et al. Glucosamine therapy for treating osteoarthritis. Cochrane Database Syst Rev 2005; 18: CD002946.

9. Clegg DO, Reda DJ, Harris CL, Klein MA, O'Dell JR, Hooper $\mathrm{MM}$, et al. Glucosamine, chondroitin sulfate, and the two in combination for painful knee osteoarthritis. N Engl J Med 2006; 354: 795-808, doi: 10.1056/NEJMoa052771.

10. Vuolteenaho K, Kujala P, Moilanen T, Moilanen E. Aurothiomalate and hydroxychloroquine inhibit nitric oxide production in chondrocytes and in human osteoarthritic cartilage. 
Scand J Rheumatol 2005; 34: 475-479, doi: 10.1080/ 03009740510026797.

11. Rezende MU, Campos GC. Viscosuplementação. Rev Bras Ortop 2012; 47: 158-162, doi: 10.1590/S0102-36162012 000200003.

12. Meunier PJ, Roux C, Seeman E, Ortolani S, Badurski JE, Spector TD, et al. The effects of strontium ranelate on the risk of vertebral fracture in women with postmenopausal osteoporosis. N Engl J Med 2004; 350: 459-468, doi: 10.1056/NEJMoa022436.

13. Reginste JY, Kaufman JM, Goemaere S, Devogelaer JP, Benhamou CL, Felsenberg D, et al. Maintenance of antifracture efficacy over 10?years with strontium ranelate in postmenopausal osteoporosis. Osteoporos Int 2012; 23: 1115-1122, doi: 10.1007/s00198-011-1847-z.

14. Reginster JY, Seeman E, De Vernejoul MC, Adami S, Compston J, Phenekos C, et al. Strontium ranelate reduces the risk of nonvertebral fractures in postmenopausal women with osteoporosis: Treatment of Peripheral Osteoporosis (TROPOS) study. J Clin Endocrinol Metab 2005; 90: 28162822, doi: 10.1210/jc.2004-1774.

15. Pelletier JP, Kapoor M, Fahmi H, Lajeunesse D, Blesius A, Maillet $\mathrm{J}$, et al. Strontium ranelate reduces the progression of experimental dog osteoarthritis by inhibiting the expression of key proteases in cartilage and of IL-1B in the synovium. Ann Rheum Dis 2013; 72: 250-257, doi: 10.1136/ annrheumdis-2012-201710.

16. Pelletier JP, Roubille C, Raunauld JP, Abram F, Dorais M, Delorme P, Martel-Pelletier J. Disease-modifying effect of strontium ranelate in a subset of pacients from the phase III knee osteoarthritis study SEKOIA using quantitative MRI: reduction in bone marrow lesions protects against cartilage loss. Ann Rheum Dis 2015; 74: 422-429, doi: 10.1136/ annrheumdis-2013-203989.

17. Fonseca JE, Brandi ML. Mechanism of action of strontium ranelate: what are the facts? Clin Cases Miner Bone Metab 2010; 7: 17-18.

18. McCaslin FE Jr, Janes JM. The effect of strontium lactate in the treatment of osteoporosis. Proc Staff Meetings Mayo Clin 1959; 34: 329-334.

19. Lems WF, Geusens P. Established and forthcoming drugs for the treatment of osteoporosis. Curr Opin Rheumatol 2014; 26: 245-251, doi: 10.1097/BOR.0000000000000057.

20. Reginster JY, Lecart MP, Deroisy R, Lousberg C. Strontium ranelate: a new paradigm in the treatment of osteoporosis.
Expert Opin Investig Drugs 2004; 13: 857-864, doi: 10.1517/ 13543784.13.7.857.

21. Meunier PJ, Roux C, Ortolani S, Diaz-Curiel M, Compston J, Marquis $P$, et al. Effects on long-term strontium ranelate treatment on vertebral fracture risk in postmenopausal women with osteoporosis. Osteoporos Int 2009; 20: 16631673, doi: 10.1007/s00198-008-0825-6.

22. Fernihough J, Gentry C, Malcangio M, Fox A, Rediske J, Pellas T, et al. Pain related behavior in two models of osteoarthritis in rat knee. Pain 2004; 112: 83-93, doi: 10.1016/ j.pain.2004.08.004.

23. Silva A, Andersen ML, Tufik S. Sleep pattern in an experimental model of osteoarthritis. Pain 2008; 140: 446455, doi: 10.1016/j.pain.2008.09.025.

24. Monville C, Torres EM, Dunnett SB. Comparison of incremental and accelerating protocols of the rotarod test for the assessment of motor deficits in the 6-OHDA model. J Neurosci Methods 2006; 158: 219-223, doi: 10.1016/ j.jneumeth.2006.06.001.

25. Randall LO, Sellito JJ. A method for measurement of analgesic activity on inflamed tissue. Arch Int Pharmacodyn Ther 1957; 111: 409-419.

26. Nogueira ES, Castro ER, Mancuso R, Navarro X. RandallSelitto test: a new approach for the detection of neuropathic pain after spinal cord injury. J Neurotrauma 2012; 29: 898904, doi: 10.1089/neu.2010.1700.

27. Nunes RM, Martins MR, Silva Junior FS, Leite ACM, Girão VC, Cunha FQ, et al. Strontium ranelate analgesia in arthritis models is associated to decreased cytokine release and opioid-dependent mechanisms. Inflamm Res 2015; 64: 781-787, doi: 10.1007/s00011-015-0860-7.

28. Girotra M, Rubin MR, Bilezikian JP. Anabolic skeletal therapy for osteoporosis. Arq Bras Endocrinol Metab 2006; 50: 745-754, doi: 10.1590/S0004-27302006000400019.

29. Brennan TC, Rybchyn MS, Green W, Atwa S, Conigrave $A D$, Mason RS. Osteoblasts play key roles in the mechanisms of action of strontium ranelate. $\mathrm{Br} \mathrm{J}$ Pharmacol 2009; 157: 1291-1300, doi: 10.1111/j.1476-5381.2009.00305.x.

30. Stepan JJ. Strontium ranelate: in search for the mechanism of action. J Bone Miner Metab 2013; 31: 606-612, doi: 10.1007/s00774-013-0494-1.

31. Komrakova M, Weidemann A, Dullin C, Ebert J, Tezval M, Stuermer KM, et al. The Impact of Strontium Ranelate on Metaphyseal Bone Healing in Ovariectomized Rats. Calcif Tissue Int 2015; 97: 391-401, doi: 10.1007/s00223-015-0019-0. 